\title{
Тепловизионная автоматизированная система для экспериментальных исследований сорбционных и каталитических свойств поверхности твердых тел
}

\author{
Б.Г. Вайнер ${ }^{1,2)}$, А.Е. Настовьяк ${ }^{1)}$, А.В. Шепелин ${ }^{2)}$, Э.А. Эминов ${ }^{2)}$ \\ ${ }^{1}$ Институт физики полупроводников им. А.В. Ржанова СО РАН, \\ Новосибирск, 630090, пр. Ак. Лаврентьева, 13 \\ ${ }^{2}$ Новосибирский государственный университет, Новосибирск, 630090, ул. Пирогова, 2 \\ тел: +7 (383) 330-7781, эл. почта: BGV@isp.nsc.ru
}

DOI 10.34077/RCSP2019-94

Актуальной для академической науки и тонкой экспериментальной задачей является изучение динамики протекания тепловых процессов, отражающих взаимодействие молекул газа с поверхностью конденсированных сред [1]. Наблюдаемые здесь температурные явления обусловлены выделением/поглощением теплоты адсорбции/десорбции. Привлечение нестандартных скоростных высокочувствительных и высокоинформативных экспериментальных методов и подходов к решению этой проблемы позволяет точнее понять физико-химические механизмы, определяющие кинетику сорбционных и каталитических процессов и динамику межмолекулярных взаимодействий в системе "газ-твердое тело".

В настоящей работе представлены результаты применения новой методологии, позволяющей бесконтактным способом количественно анализировать начальные и последующие стадии взаимодействия молекул газа с твердыми телами. Эта методология основана на применении инфракрасной термографии (тепловидения) нового поколения. Матричное тепловидение сегодня единственный инструмент экспериментальных исследований, позволяющий без

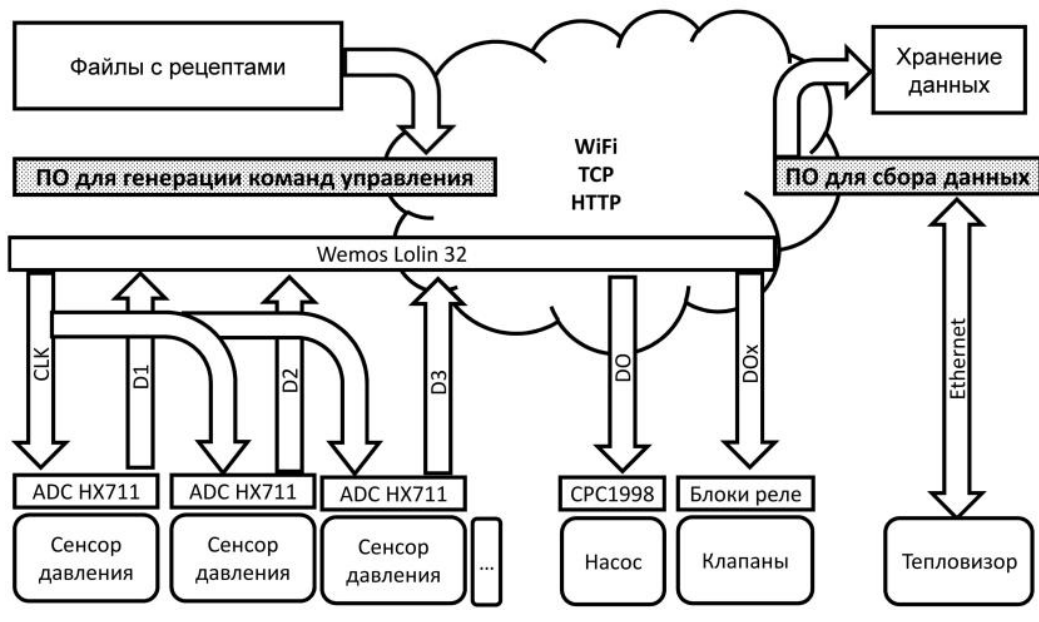

Рис. 1. Архитектура электронного управления и ввода/вывода данных тепловизионной автоматизированной системы. прямого контакта с зоной, где расположен изучаемый объект, количественно и прецизионно исследовать быструю эволюцию зарождения и развития температурных превращений, сопровождающих сорбционнокаталитические процессы и отражающих физико-химическую природу последних. Подобная термодинамика пока еще практически не изучалась на материалах с микро- и наноструктурированной поверхностью, представляющих основной научный интерес в настоящей работе.

Результаты вышеописанных экспериментов предельно чувствительны к процедуре исследований. В первую очередь, здесь требуется обеспечить высокую воспроизводимость экспериментальных условий, поскольку первая, вторая и последующие реакции взаимодействия газа с поверхностью твердого тела могут протекать неодинаково из-за изменений физико-химических поверхностных свойств образцов в ходе самого опыта, и такие явления не должны затеняться возможными спонтанными артефактами. По указанной причине проведение эксперимента необходимо "поручить", исключительно, автоматизированной системе, управляемой компьютером, чтобы полностью исключить влияние человеческого фактора.

Полная архитектура системы программного и электронного управления и ввода/вывода данных созданного измерительного комплекса изображена на рис. 1. Система позволяет координировать газовые потоки [2], направляемые в реакционную камеру с входным окном, прозрачным в ИК области спектра и позволяющим проводить тепловизионный количественный анализ процесса.

Работа выполнена при финансовой поддержке РФФИ, грант № 18-08-00956.

\section{Лumepamypa}

[1] B.G. Vainer // RCCT-2017 / Novosibirsk: NIIC SB RAS, 2017. P. 56.

[2] Б.Г. Вайнер, А.Е. Настовьяк, Э.А. Эминов // Труды АПЭП-2018 / Новосибирск: НГТУ, IEЕЕ, 2018. T. 5. C. 61-67. 